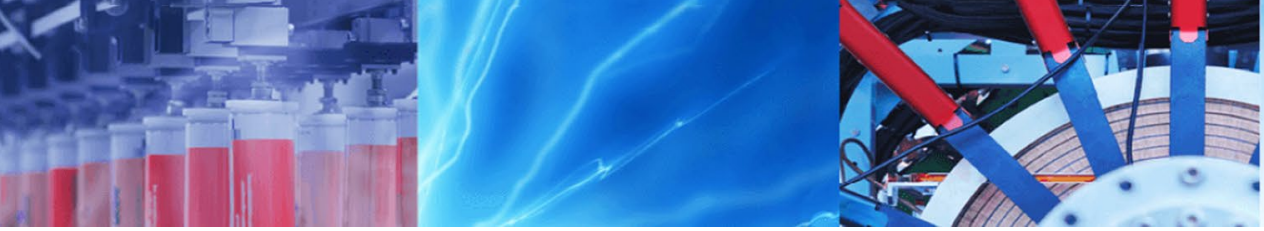

Research Article

\title{
Simultaneous reduction and surface functionalization of graphene oxide for highly conductive and water dispersible graphene derivatives
}

\author{
Vassiliki Belessi ${ }^{1,2}$ (Dimitrios Petridis ${ }^{2} \cdot$ Theodoros Steriotis $^{2} \cdot$ Konstantinos Spyrou $^{3} \cdot$ Georgios K. Manolis $^{2}$. \\ Vasilios Psycharis ${ }^{2} \cdot$ Vasilios Georgakilas ${ }^{4}(1)$
}

(c) Springer Nature Switzerland AG 2018

\begin{abstract}
A simple and effective preparation method for the simultaneous reduction and functionalization of graphene oxide ( $\mathrm{rGO}$ ) by 2,4-diamino benzene sulfonic acid has been developed. The derivatives exhibit excellent conductivity and high dispersibility in various solvents. The successful preparation of $\mathrm{rGO}$ and the presence of the sulfonated aromatic diamine on rGO surface has been confirmed by infrared and X-ray photoelectron spectroscopy, while, the analysis by micro-Raman spectroscopy indicated that the reduction/functionalization alters the lattice structure of GO by the increment the defect density when the 2,4-diamino benzene sulfonic acid is used. Moreover, the study of the dried products by $\mathrm{X}$-ray diffraction spectroscopy suggested the turbostratic restacking of the exfoliated rGO into graphite-like nanostructures. The obtained derivative of simultaneous reduction and functionalization of GO was used for the preparation of highly conductive water-based gravure ink, which in turn, was successfully applied in printing on various flexible substrates, demonstrating its great potentiality in graphene-based flexible and printed electronics applications.
\end{abstract}

Keywords Reduced graphene oxide · Surface functionalization · Conductive inks · Gravure · Printed electronics

\section{Introduction}

Graphene sheets, first isolated in 2004 by micro mechanical exfoliation of highly oriented pyrolytic graphite are planar monolayers of $\mathrm{sp}^{2}$-bonded carbon atoms tightly packed into a two-dimensional honeycomb lattice with remarkable electronic, optical and mechanical properties [1]. The production of pristine graphene nanosheets have been further achieved by epitaxial growth [2], chemical vapor deposition [3], and liquid exfoliation of graphite in selected organic solvents or surfactant aqueous solutions [4-6]. However, despite the high quality of pristine graphene nanosheets and their remarkable electrical and mechanical properties that obtained by these techniques, their low yield at high costs and up-scaling difficulties are decisive parameters for their large scale production failure.

This handicap is overpassed by preparing of graphene nanosheets with the chemical reduction of graphene oxide (GO), as named the extensively exfoliated in water graphite oxide $[7,8]$. The latter is a hydrophilic layered derivative of graphite produced by its oxidation under strong acidic conditions [9]. The oxidation decorates the graphenic surfaces mainly with carbonyl and carboxy groups at the edges and hydroxyl and epoxide groups at both sides of the sheets [10-13]. The most significant consequence of the oxidation process is the serious

\footnotetext{
$\triangle$ Vassiliki Belessi, vbelessi@uniwa.gr; $\square$ Vasilios Georgakilas, viegeorgaki@upatras.gr| ${ }^{1}$ Department of Graphic Design and Visual Communication, University of West Attica, Agiou Spyridonos Street, 12210 Egaleo Athens, Greece. ${ }^{2}$ Institute of Nanoscience and Nanotechnology (INN), National Center for Scientific Research “Demokritos", Aghia Paraskevi, 15310 Athens, Greece. ${ }^{3}$ Department of Material Science \& Engineering, University of loannina, loannina, Greece. ${ }^{4}$ Materials Science Department, University of Patras, 26504 Rio, Greece.
} 
damage of the graphitic $\mathrm{sp}^{2}$-bonding of its lattice structure. All these, point and extended, defects, as vacancies, adatoms, dislocations and rings, result to a poor electrical conductivity of the easily exfoliated water dispersible GO nanosheets. The later, in turn, can be reduced to graphene like sheets (i.e. reduced graphene oxide, rGO) by several reductive agents including hydrazine and its derivatives, hydroiodic or ascorbic acid, hydroquinone, potassium and sodium hydroxide, diverse metal hydrides, hydroxylamine, sodium ammonia solution, urea and thiourea [9].

In addition, several authors have reported reduction of GO with aliphatic [14-16] or aromatic amines $[17,18]$. While the current methods of GO chemical reduction provides the potentiality for its large scale and low cost production, the obtained rGO nanosheets exhibit, in all cases, significantly lower electrical conductivity than pristine graphene counterparts.

In general, the type of reducing agent can affect the reduction level of the $\mathrm{rGO}$, while, under suitable reaction conditions, reduction can be accompanied by chemical functionalization offering a variety of graphene derivatives with enriched characteristics and properties.

For instance, $p$-phenylene diamine has been used simultaneously as reducing and functionalizing agent of graphene oxide, giving organically modified graphene nanosheets with high values of electrical conductivity [17, 18]. Lately, graphene has been widely studied as conductive ink that could be used for printed electronics in several printing methods [19-25]. Both, electrical conductivity and dispersibility, into either, water or organic solvents, are the major requirements for the applicability of graphene as conductive inks. In most cases in the literature, pristine graphene or rGO have been used as conductive inks, where their poor dispersibility is partly improved with the application of several dispersing agents such as polymers, ionic liquids or surfactants, which, unfortunately, have negative impact to the conductivity of the final product.

In an effort to avoid the use of dispersing agent in a conductive ink, we present here a graphene derivative that is formed by the simultaneous reduction and functionalization of $\mathrm{GO}$ by a sulfonated aromatic diamine. Dual reaction's effect on resulting product combines its excellent conductivity and high dispersibility in water and proves that can exhibits outstanding results as a simple, cost-efficient, conductive ink for gravure printing technique. The 2,4-diamino benzene sulfonic acid (2,4-DBSA) provides extended reduction, while the functionalization with sulfonic benzene groups remarkably rises the aquatic dispersibility and the electrical conductivity of the final graphene derivative.

Such graphene derivatives can be potentially used as inks in the most common printing technologies such as gravure, flexography, screen printing and ink-jet on a variety of substrates such as paper, polymer, glass or metal [19, 21-23, 26-29]. Printed electronics are widely employed in the fields of packaging, printing and graphic arts, logistics, energy, medical and pharmaceutical, automotive, lighting and textiles [30]. Among printing technologies, gravure has found applications in the field of printed electronics on account of low cost production of electronic devices in huge volumes. The preparation method of an optimum conductive ink should be simple, low cost, scalable and of high yield, affording stable and printable inks with good rheological properties and high electrical conductivity at room temperature.

Characteristic examples of rather limited reports related to gravure inks based on graphene or $\mathrm{rGO}$ derivatives are presented below. Secor et al. [29] showed that graphene dispersed in ethanol with ethyl cellulose as stabilizing agent and terpineol as solvent can act as ink for gravure printing creating lines with conductivities up to $10^{4} \mathrm{~S} \mathrm{~m}^{-1}$ but only after annealing at $250{ }^{\circ} \mathrm{C}$. Recently, Georgakilas et al. [21] presented the fabrication of highly conductive water based gravure ink, based on a nanohybrid that combines pristine graphene nanosheets and hydroxylated MWNTs, with conductivities up to $\sim 5000 \mathrm{~S}$ $\mathrm{m}^{-1}$ without any annealing procedure. In addition, highresolution gravure printing with graphene ink on corona treated PET foil has been developed by Knoll et al. [31] for biomedical applications achieving sheet resistances up to $\sim 15-20 \mathrm{Ohm} \mathrm{sq}^{-1}$. Interestingly, the research on the use of rGO especially for the development of gravure ink formulations is very deteriorated compared to other printing methods [32]. But the advantages of this synthetic procedure e.g. higher yield and lower cost compared to other methods favor its use for realistic low cost, and high-volume industrial applications where gravure is useful. Xiao et al. $[33,34]$ has referred the use of gravure for the printing of sulfonated rGO and $\mathrm{MoS}_{2} @$ sulfonated rGO active materials for applications such as the fabrication of SERS (Surface-enhanced Raman scattering) active substrates and interdigitated micro supercapacitors, respectively.

In the present work, a sulfonated aromatic diamine was used as reducing agent that allowed a facile, efficient and one-pot reduction and functionalization of GO. To the best of our knowledge, the behavior of this reductant has not been explored in this context. The as prepared aminosulfonated graphene sheets were fully characterized by various methods and exhibited high electrical conductivity, reflecting that an extensive conjugated $\mathrm{sp}^{2}$ carbon network has been restored after the reduction procedure. The resulting reduced/functionalized graphene derivative showed high dispersibility in either aqueous and organic solvents without addition of surfactants or other stabilizers. Relying on these findings and using commercial resins, 
we proceeded with the preparation of water based gravure ink, and its printing on various flexible substrates.

\section{Materials and methods}

Graphite (powder, synthetic, particle size $<20 \mu \mathrm{m}$ ), 2,4-diaminobenzenesulfonic acid (2,4-DBSA) ( $\geq 98 \%)$, 2,5-diaminobenzenesulfonic acid (tech., 90\%) (2,5DBSA) and $p$-phenyldiamine (PPD) were purchased from Aldrich. Sulfuric acid (95-97\%) and Potassium chlorate (purum $>99.0 \%$ ) were purchased from Merck and nitric acid (65\%) from Riedel-de Haen. All solvents were of analytical grade and were used as received. The NMB $001 \mathrm{~L}$ 0003 is a commercial water-based varnish from Druckfarben Hellas S. A. which contains mainly a mixture of styrene-acrylate and acrylic resins, wax emulsion on modified polyethylene and silicone-based antifoaming agent. The solid content of the resin was estimated to $47 \%$. The NMB $001 \mathrm{~L} 0003$ standard commercial grade is suitable for non absorbent substrates. The NRB 001 L 3099 is a commercial water-based varnish from Druckfarben Hellas S. A. which contains mainly a mixture of styreneacrylic (MW > 200,000) and acrylic resins (MW 8500), small amount of ammonia, polyethylene and siliconebased antifoaming agent. The solid content of the resin was estimated to be $73 \%$. This standard commercial grade is suitable for absorbent substrates.

\subsection{Preparation of graphene oxide (GO)}

Graphite oxide was synthesized by the modified Staudenmaier method [35]. According to this method, $2 \mathrm{~g}$ of powdered graphite were added in an ice-cooled flask containing a mixture of concentrated sulfuric $(80 \mathrm{~mL})$ and nitric acid $(40 \mathrm{~mL})$. Potassium chlorate $(40 \mathrm{~g})$ was slowly added to the mixture while stirring and cooling. The reactions were quenched after $18 \mathrm{~h}$ by pouring the mixture into distilled water and the product was isolated by centrifugation $(13,000 \mathrm{rpm})$ and washed with water several times until the $\mathrm{pH}$ of the supernatant was almost neutral. The sample was then dried at room temperature.

\subsection{Reduction and functionalization of $\mathrm{GO}$ with sulfonated aromatic diamines $\left(\mathrm{rGO}_{2,4-\mathrm{DBSA}}\right)$}

$75 \mathrm{mg}$ of GO were dispersed in $75 \mathrm{ml}$ of deionized water and stirred for $24 \mathrm{~h}$. The partly exfoliated GO was ultrasonicated for 30 min using a Branson 3800 bath sonicator $(110 \mathrm{~W}, 40 \mathrm{kHz})$. Then, $225 \mathrm{mg}$ of 2,4-diaminobenzenesulfonic acid (2,4-DBSA) were dispersed in the well-exfoliated $\mathrm{GO}$ suspension under stirring. The mixture was refluxed $\left(\sim 100^{\circ} \mathrm{C}\right)$ under magnetic stirring for $5 \mathrm{~h}$. After cooling the mixture to room temperature, it was centrifuged at 9000 rpm or vacuum filtered through Nylon membrane filters with $0.2 \mu \mathrm{m}$ pore size (Whatman). Finally, the obtained solid was washed extensively with water, basic water solution $(\mathrm{pH}=12)$, ethanol and acetone and air-dried. The same procedure was also followed with 2,5-diaminobenzenesulfonic acid (2,5-DBSA) as reductive agent.

\subsection{Test of dispersibility}

$10 \mathrm{mg}$ of $\mathrm{rGO}_{2,4-D B S A}$ powder were dispersed in $2 \mathrm{ml}$ of the following solvents (polarity index in parenthesis): dimethylsulfoxide (DMSO) (7.2), N,N-dimethylformamide (DMF) (6.4), acetonitrile (5.8), ethanol (5.2), tetrahydrofuran (THF) (4.0), isopropanol (3.9), toluene (2.4) and dichloromethane (DCM) (3.1). The dispersions were sonicated in an ultrasound bath cleaner (Branson 3800, $110 \mathrm{~W}, 40 \mathrm{kHz}$ ).

\subsection{Preparation of gravure inks}

\subsubsection{Conductive gravure ink suitable for absorbent substrates (Ink-1)}

$21.6 \mathrm{mg}$ of the commercial resin emulsion NRB 001 L 3099 was diluted with distilled water to a final volume of $288 \mu \mathrm{L}$ $\left(75 \mu \mathrm{g} \mathrm{\mu \textrm {L } ^ { - 1 }}\right.$ ) [21]. Then, $800 \mu \mathrm{L}$ of the $\mathrm{rGO}_{2,4 \text {-DBSA }}$ dispersion (33 mg mL $\mathrm{L}^{-1}$ ) were slowly mixed with $288 \mu \mathrm{L}$ of the diluted resin emulsion NRB $001 \mathrm{~L} 3099\left(75 \mu \mathrm{g} \mathrm{L}^{-1}\right)$. The mixture was stirred mildly overnight. The percentage of the solids in the final suspension was $55 \% \mathrm{w} / \mathrm{w}$ in $\mathrm{rGO}_{2,4-\mathrm{DBSA}}$.

\subsubsection{Conductive gravure ink for non-absorbent substrates (Ink-2)}

$36.0 \mathrm{mg}$ of the commercial resin emulsion NMB $001 \mathrm{~L} 0003$ was diluted with distilled water to a final volume of $540 \mu \mathrm{L}$

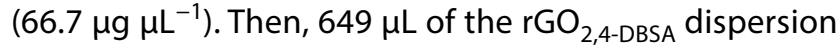
(44 $\mathrm{mg} \mathrm{mL}^{-1}$ ) were slowly mixed with $351 \mu \mathrm{L}$ of the diluted resin emulsion NMB $001 \mathrm{~L} \mathrm{0003.} \mathrm{The} \mathrm{mixture} \mathrm{was} \mathrm{stirred}$ mildly overnight. The percentage of the solids in the final suspension was $55 \% \mathrm{w} / \mathrm{w}$ in $\mathrm{rGO}_{2,4-D B S A}$. It should be noted that the commercial varnishes are specially designed for water-based gravure inks.

\subsection{Characterization of materials}

X-ray powder diffraction (XRD) patterns were taken on a $\mathrm{D}$-500 Siemens diffractometer using $\mathrm{Cu}$ Ka radiation $(\lambda=1.5418 \AA$ A). FT-IR spectra were collected on a Perkin Elmer Spectrum GX and a Bruker Tensor 27 FT-IR spectrometer, both equipped with DTGS detectors in the region of $400-4000 \mathrm{~cm}^{-1}$. The samples were measured in the form of $\mathrm{KBr}$ pellets (Aldrich, 99\%, FT-IR grade). Similar amounts 
of $\mathrm{GO}$ and $\mathrm{rGO}$ samples were thoroughly mixed with $\mathrm{KBr}$ to prepare the pellets prior to analysis.

XPS measurements were performed under ultrahigh vacuum $4 \times 10^{-9}$ mbar (base pressure) using a SPECS $\mathrm{GmbH}$ instrument equipped with a monochromatic MgKa source ( $\mathrm{hv}=1253.6 \mathrm{eV}$ ) and a Phoibos-100 hemispherical analyzer. The energy resolution was set to $1.2 \mathrm{eV}$ and the photoelectron take-off angle was $45^{\circ}$ with respect to the surface normal. Recorded spectra were set with energy step set of $0.05 \mathrm{eV}$ and dwell time of $1 \mathrm{~s}$. All binding energies were referenced with regard to the $C 1 \mathrm{~s}$ core level centered at $284.6 \mathrm{eV}$ [36]. Spectral analysis included a Shirley background subtraction and peak deconvolution involved mixed Gaussian-Lorentzian functions and was conducted with a least squares curve-fitting program (WinSpec, University of Namur, Belgium).

Thermogravimetric analysis was performed on a SETARAM SETSYS Evolution 18 Analyser in an alumina crucible, at a heating rate of $10^{\circ} \mathrm{C} \mathrm{min}{ }^{-1}$ using $\mathrm{Ar}$ as the carrier gas, in the range of $25-650^{\circ} \mathrm{C}$. The nitrogen adsorption/desorption isotherms at $77 \mathrm{~K}$ were measured in a volumetric gas adsorption analyzer (Autosorb-1-MP, Quantachrome). Prior to measurement, the samples were outgassed at $100{ }^{\circ} \mathrm{C}$ for $12 \mathrm{~h}$. The specific surface area values were calculated by the Brunauer-Emmett-Teller (BET) method as applied at relative pressures between 0.07 and 0.3 (BET consistency criteria were respected).

Micro-Raman spectra, in the $300-3700 \mathrm{~cm}^{-1}$ range at room temperature, were measured in back scattering configuration on a dispersive Renishaw in-Via Reflex spectrometer with $250 \mathrm{~mm}$ focal length equipped with a high sensitivity, deep-depletion CCD detector. Excitation was performed by a solid state laser emitting at a wavelength of $514 \mathrm{~nm}$. The laser beam was focused on several spots of $4.5 \mu \mathrm{m}$ diameter on the sample's surface using a $20 \times$ objective lens of a Leica DMLM microscope in order to increase the statistic ensample by 25 times than using a $50 \times$ objective lens. The power density, approximately

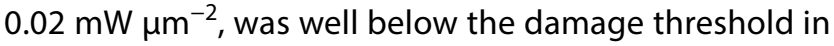
order to avoid sample overheating. Raman scattered signal was filtered by a $100 \mathrm{~cm}^{-1}$ cut-off dielectric filter and analyzed with a 1200 lines $\mathrm{mm}^{-1}$ diffraction grating and resolution $2 \mathrm{~cm}^{-1}$. Spectral deconvolution was carried out by linear least squares fitting of the Raman peaks to a mixture of Lorentzian and Gaussian line shapes, after the handmade background subtraction, using the WiRE software. Microscopic analysis of the samples was performed using Transmission Electron Microscopy (TEM) (JEOL-JEM 2100) and Scanning Electron Microscopy (JEOL JSM-6510LV).

For the electrical measurements, the rGO samples and rGO inks were drop casted on the selected coated paper as circular spots and dried at $75^{\circ} \mathrm{C}$ for $60 \mathrm{~min}$. To secure comparable results similar amounts of $\mathrm{rGO}$ were used for the spots. The samples were compressed at 2 tn according to previous works $[21,37]$ and the sample thickness was measured by an electronic micrometer (IP54, Tesa). Sheet resistance, resistivity and conductivity of the as deposited rGO samples were measured and estimated respectively by a 4-point probe system (Pro4 Resistivity System, Lucas Labs) and Keithley 2400 Source Meter.

\subsection{Gravure printing of rGO ink}

Printing substrates, machine speed and engraving are important parameters that contribute to the print quality. In the present case, the graphene ink prepared using the $r \mathrm{GO}_{2,4 \mathrm{DBSA}}$ (Ink-1) was printed onto a $205 \mu \mathrm{m}$ paper having hydrophilic nanoporous surface coating. The absorbent substrate was a special paper for organic and printed electronics obtained from Felix Schoeller Group (p_e: smart, paper type 2, thickness $205 \mu \mathrm{m}$ ). The graphene ink prepared using the $\mathrm{rGO}_{2,4 \mathrm{DBSA}}$ (Ink-2) was printed onto corona treated $16 \mu \mathrm{m} \mathrm{BOPP} \mathrm{(} 36$ to 40 dynes $\mathrm{cm}^{-1}$ ) and $12 \mu \mathrm{m}$ PET ( 44 to 50 dynes $\mathrm{cm}^{-1}$ ) substrates. The non absorbent substrates were available from Druckfarben Hellas S. A. The printing tests were done using the IGT G1-5 printability tester with two raster patterned printing cylinders named by IGT as 402.153 (70 lines per centimeter, screen angle 53 , stylus angle 140 and cell depth 33 ; $31 ; 30 ; 29 ; 26 ; 24 ; 20 ; 17 ; 14 ; 11 \mu \mathrm{m}$ ) and 402.100 (40 and 70 lines per centimeter, screen angle 53 , stylus angle 130 and cell depth $5 ; 10 ; 15 ; 20 ; 25 ; 30 ; 35 ; 40 ; 45 ; 50 ; 55 ; 60 ; 65$; $70 ; 75 ; 80 \mu \mathrm{m})$. Before printing, the ink was applied with a pipette in front of a doctor blade and then transferred to the substrate. The graphene inks were gravure printed for various print speeds $\left(\mathrm{m} \mathrm{min}^{-1}\right)$ and cylinder pressures $(\mathrm{N})$ on the substrates.

\section{Results and discussion}

For the preparation of the sulfonated $r \mathrm{GO}$, appropriate amount of the aromatic sulfonated diamine (2,4-DBSA) was added to a dispersion of well-exfoliated $G O$ in water having acidic $\mathrm{pH}(\sim 2)$ due to carboxylates of $\mathrm{GO}$ and the mixture was refluxed for several hours (Fig. 1-scheme). The color change of the reaction mixture from brownish to black after few minutes was indicative of the reductive action of the aromatic diamine, in the acidic environment. After several hours, the as received product $\left(r \mathrm{GO}_{2,4-\mathrm{DBSA}}\right)$ was found to be simultaneously highly soluble in water and organic solvents and highly conductive after deposition and drying, in sharp contrast with the GO precursor. The same procedure was also applied with 2,5-DBSA diamine as reductive agent affording a similar product $\left(r \mathrm{GO}_{2,5-\mathrm{DBSA}}\right)$. The yield in both reactions after the isolation 


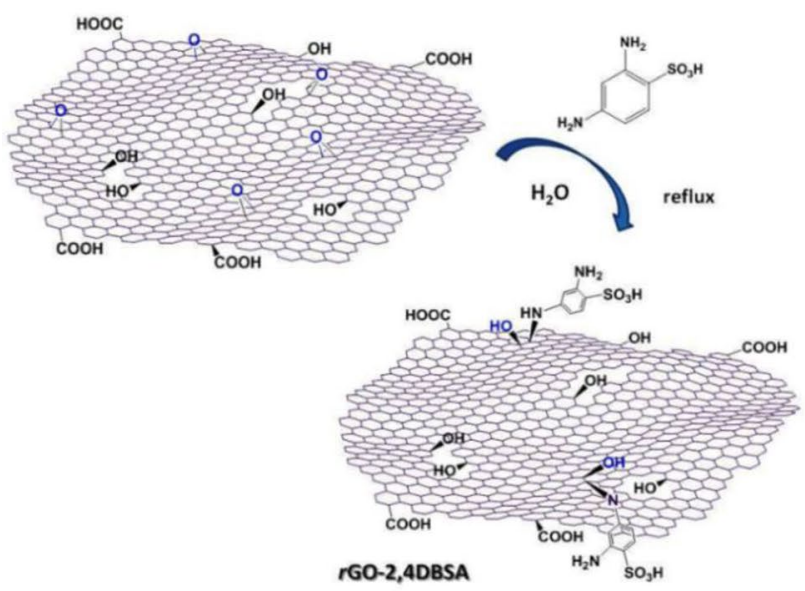

Fig. 1 (left) Schematic representation of the reduction/functionalization of GO from 2,4-DBSA. (right) a Photographs of $r \mathrm{GO}_{2,4-D B S A}$ dispersed in a variety of solvents $\left(0.5 \mathrm{mg} \mathrm{mL}^{-1}\right)$ after $30 \mathrm{~min}$ sonication. The solvents from left to right are DMF, DMSO, acetonitrile, THF, ethanol, isopropanol, toluene and DCM. b A highly concen-

of the final products ranges between 30 and $40 \%$. The two characteristic properties of the $r \mathrm{GO}_{2,4-\mathrm{DBSA}}$ and $r \mathrm{GO}_{2,5-\mathrm{DBSA}^{\prime}}$ conductivity and dispersibility in water, were the result of the two simultaneous reactions that followed the heating of $\mathrm{GO}$ colloid in the presence of the diamine; reduction and functionalization of $r \mathrm{GO}$ by the sulfonated diamines, respectively.

In order to clarify whether 2,4-DBSA was covalently attached or simply adsorbed on GO surface, a blank experiment was performed by mixing a water suspension of GO with 2,4-DBSA and after standing for several hours the product was isolated and washed thoroughly. The FT-IR spectrum of the blank product was almost identical with the spectrum of GO, indicating that 2,4-DBSA is not adsorbed by the $\mathrm{GO}$ surfaces at these conditions.

\subsection{Dispersibility of functionalized rGOs}

$r \mathrm{GO}_{2,4-\mathrm{DBSA}}$ and $r \mathrm{GO}_{2,5-\mathrm{DBSA}}$ are highly dispersed in ethanol, water, DMF, DMSO and isopropanol (Fig. 1a). Ethanol or water dispersions of the products at a concentration up to $0.5 \mathrm{mg} \mathrm{mL}^{-1}$ were stable for more than 6 months due to the electrostatic repulsion of the negatively charged sulfonated $r$ GO sheets (Fig. 1c) [38]. The products were also mixed with water or ethanol at concentrations up to $33 \mathrm{mg} \mathrm{mL}^{-1}$ giving highly viscous homogenous mixtures (Fig. 1b). GO is poorly dispersed in isopropanol, better in DMSO and ethanol and well in water or DMF [38-41], while $r G O$ (using thermal reduction or simple reductive agents such as $\mathrm{NaBH}_{4}$ ) is usually poorly dispersible in most solvents [38]. The stability of the ethanol dispersion of

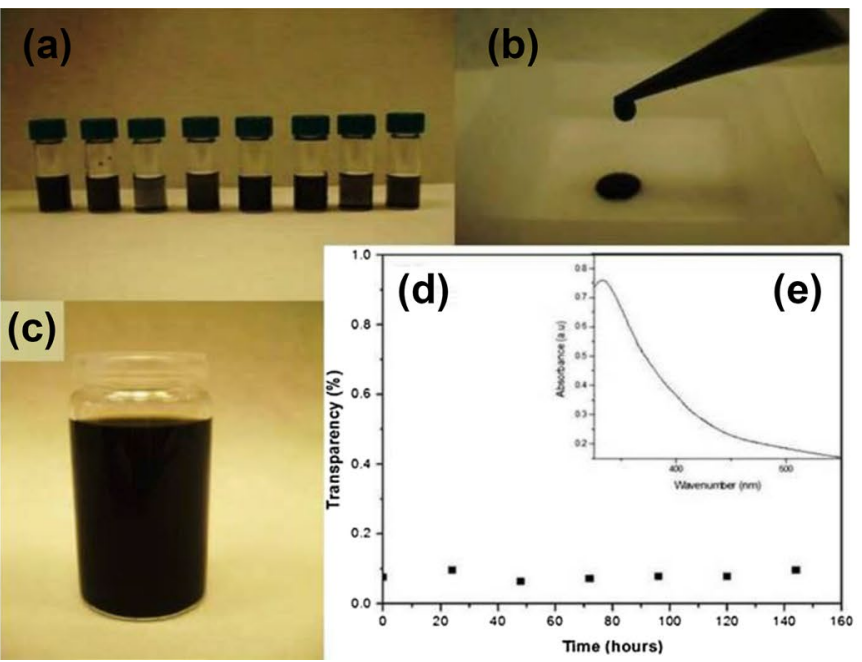

trated (33 $\mathrm{mg} \mathrm{mL}^{-1}$ ) water dispersion of $r \mathrm{GO}_{2,4-\mathrm{DBSA}}$. c Photograph of $r \mathrm{GO}_{2,4-\mathrm{DBSA}}$ dispersion in ethanol $\left(0.5 \mathrm{mg} \mathrm{mL}^{-1}\right)$ after 6 months stay and $\mathbf{d}$ stability of $r \mathrm{GO}_{2,4-\mathrm{DBSA}}$ in ethanol; time dependence of the transmittance at $550 \mathrm{~nm}$, e UV-Vis spectrum of $r \mathrm{GO}_{2,4-\mathrm{DBSA}}$ dispersion in ethanol

$r \mathrm{GO}_{2,4-\mathrm{DBSA}}$ was further examined by measuring its transmittance at $550 \mathrm{~nm}$ as a function of time. As presented in Fig. $1 d$, the transmittance of $r \mathrm{GO}_{2,4-D B S A}$ in ethanol remained almost stable during a period of 6 days. The SEM image of $r \mathrm{GO}_{2,4-\mathrm{DBSA}}$ sample is presented in Fig. 2 revealing nanosheets with wrinkled morphologies.

\subsection{X-ray diffraction measurements of GO, $\mathrm{rGO}_{2,4-\mathrm{DBSA}}$}

The XRD patterns of the $\mathrm{GO}$ and $r \mathrm{GO}_{2,4-D B S A}$ solids are shown in Fig. 3a. The XRD diagram of GO shows a sharp intense peak at $11.86^{\circ}$ corresponding to an interlayer distance of approximately $0.73 \mathrm{~nm}$ from the water molecules entrapped between the hydrophilic surfaces of $\mathrm{GO}$ and the oxygen-containing functional groups of $\mathrm{GO}$ layer [42-44]. In contrast with the parent GO, where the sharp peak indicates a well stacking layered material, in the pattern of $r \mathrm{GO}_{2,4-D B S A}$ the peak at $11.6^{\circ}$ is totally disappeared implying that the surfaces of $\mathrm{rGO}$ have been changed to a high extent from hydrophilic to hydrophobic and thus, expelling the water molecules from the interlayer zone after drying.

On the other hand, a broad and weak peak appearing at 25.73 in $r \mathrm{GO}_{2,4-\mathrm{DBSA}}$, corresponds to a d-spacing of $\sim 0.34 \mathrm{~nm}$ close to the $\mathrm{d}_{002}$ spacing of graphite $(0.335 \mathrm{~nm})$ and could be attributed to the partial graphitic character of the reduced products in the form of a few layer turbostratic graphenic nanosheets [45]. Accordingly, it could be reasonably supposed that GO layers were firstly reduced and organized in a few layers graphenic 

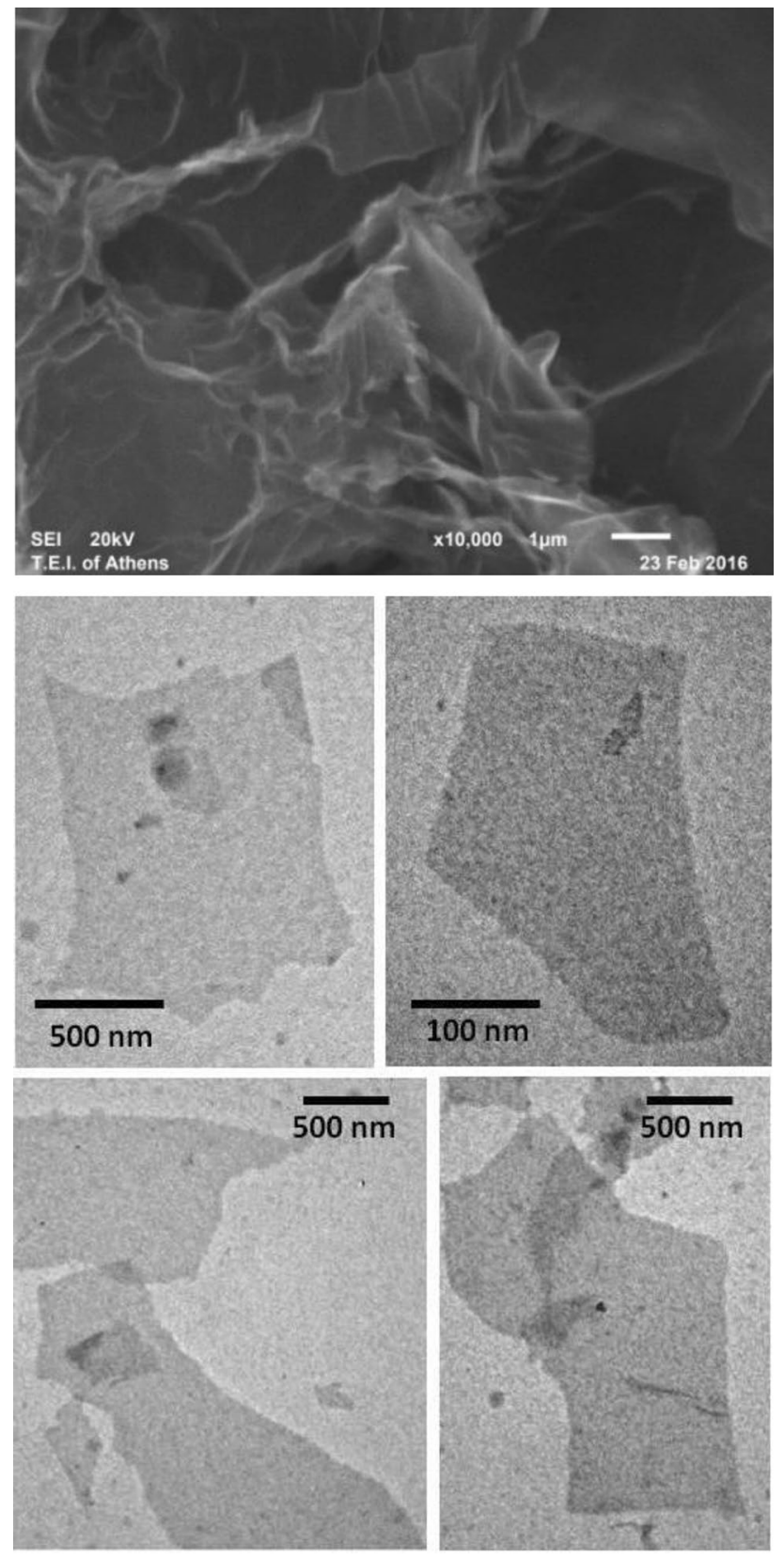

Fig. 2 (upper) SEM image and (down) TEM images of $\mathrm{rGO}_{2,4-\mathrm{DBSA}}$

nanosheets and in a second step, these nanosheets were functionalized by the DBSA groups acquiring their final hydrophilic character in aqueous environment.

\subsection{FTIR spectroscopy of $\mathrm{GO}, \mathrm{rGO}_{2,4-D B S A}$}

FTIR spectroscopy helps to reveal various chemical changes taking place during reduction of GO by 2,4-DBSA and functionalization. The FTIR spectra of $\mathrm{GO}, r \mathrm{GO}_{2,4-D B S A}$ are shown in Fig. 3b, c, respectively. The spectrum of $\mathrm{GO}$ is very similar to those already reported $[15,46]$. Thus, the strong and broad peak at $3428 \mathrm{~cm}^{-1}$ is due to the stretching vibrations of $\mathrm{O}-\mathrm{H}$ bond (carboxylic) $[17,46,47]$, the shoulder at $1700 \mathrm{~cm}^{-1}$ to $\mathrm{C}=\mathrm{O}$ stretching vibrations in carboxylic and carbonyl moieties presented at the edges of the GO sheets and at the edges of holes [17, 46-49], the peaks at $1623 \mathrm{~cm}^{-1}$ and $1400 \mathrm{~cm}^{-1}$ are allocated to $C=C$ in aromatic rings $[46,49,50]$ and to the deformation vibrations of carboxylic $\mathrm{O}-\mathrm{H}$ groups $[17,48]$. The peak at $1220 \mathrm{~cm}^{-1}$ is usually assigned to phenolic $\mathrm{C}-\mathrm{OH}$ vibration $[48,51]$ and that of $1053 \mathrm{~cm}^{-1}$ is assigned to the epoxy (or alcoxy) vibration [52-54].

Regarding the spectra of the product, the first observation is that following the reductive treatment with the sulfonated aromatic diamine, the FTIR spectrum of $r \mathrm{GO}_{2,4-\mathrm{DBSA}}$ clearly shows that $\mathrm{GO}$ peaks have undergone significant reduction in intensity indicating the presence of partially oxidized graphitic nanoplatelets (Fig. 3c). The successful reduction of $\mathrm{GO}$ is further indicated by the removal of the epoxy peak at $1053 \mathrm{~cm}^{-1}$ while the presence of the sulfonic groups is confirmed by the appearance of the intense peaks at 1165 (deformation vibration for $\mathrm{S}=0$ ) $[49,50,55,56]$ and $1030 \mathrm{~cm}^{-1}$ (shoulder, symmetric vibration of $\mathrm{O}=\mathrm{S}=\mathrm{O}$ group) $[56,57]$ in agreement with the $\mathrm{X}$-ray photoelectron spectroscopy results (shown below). Thus, the spectra show clearly that the sulfonated aromatic diamines are present in the reduced $\mathrm{GO}$ sheets.

We note that the presence of the peaks at $1400 \mathrm{~cm}^{-1}$ (O-H deformation vibration) and at $1715 \mathrm{~cm}^{-1}$ in treated sample indicates that carboxylic and $\mathrm{C}=\mathrm{O}$ groups are still present in $r G O$ layers (Fig. $3 \mathrm{C}$ ) in good agreement with the $\mathrm{X}$-ray photoelectron spectroscopy measurements presented below. Furthermore, the peak at $1565 \mathrm{~cm}^{-1}$ and the wide shoulder around $730 \mathrm{~cm}^{-1}$ correspond to the stretching and deformation vibrations of $\mathrm{N}-\mathrm{H}$ in $-\mathrm{C}-\mathrm{NH}-\mathrm{C}$ group indicating a covalent binding of DBSA on graphene surface $[14,58]$. The presence of nitrogen is confirmed by the X-ray photoelectron spectroscopy measurements and presented below.

\subsection{X-ray photoelectron spectroscopy of GO and $\mathrm{rGO}_{2,4-\mathrm{DBSA}}$}

In order to verify the data acquired from FTIR spectroscopy and learn more for the type of interaction between the DBSA and the graphene layers, the initial GO and $r \mathrm{GO}_{2,4-\mathrm{DBSA}}$ were studied by means of $\mathrm{X}$-ray photoelectron spectroscopy. Figure 4a-left exhibits the carbon $1 \mathrm{~s}$ high resolution photoelectron spectrum of GO. As shown in Fig. 4a-left, the experimental peak is deconvoluted into four different peaks. The peak from the $\mathrm{C}-\mathrm{C}$ bonds of the $\mathrm{sp}^{2}$ carbons in the basal plane of $\mathrm{GO}$ at $284.6 \mathrm{eV}$ represents just $14.4 \%$ of the total carbon amount indicating the extended oxidation of GO [59]. A second peak centered at 

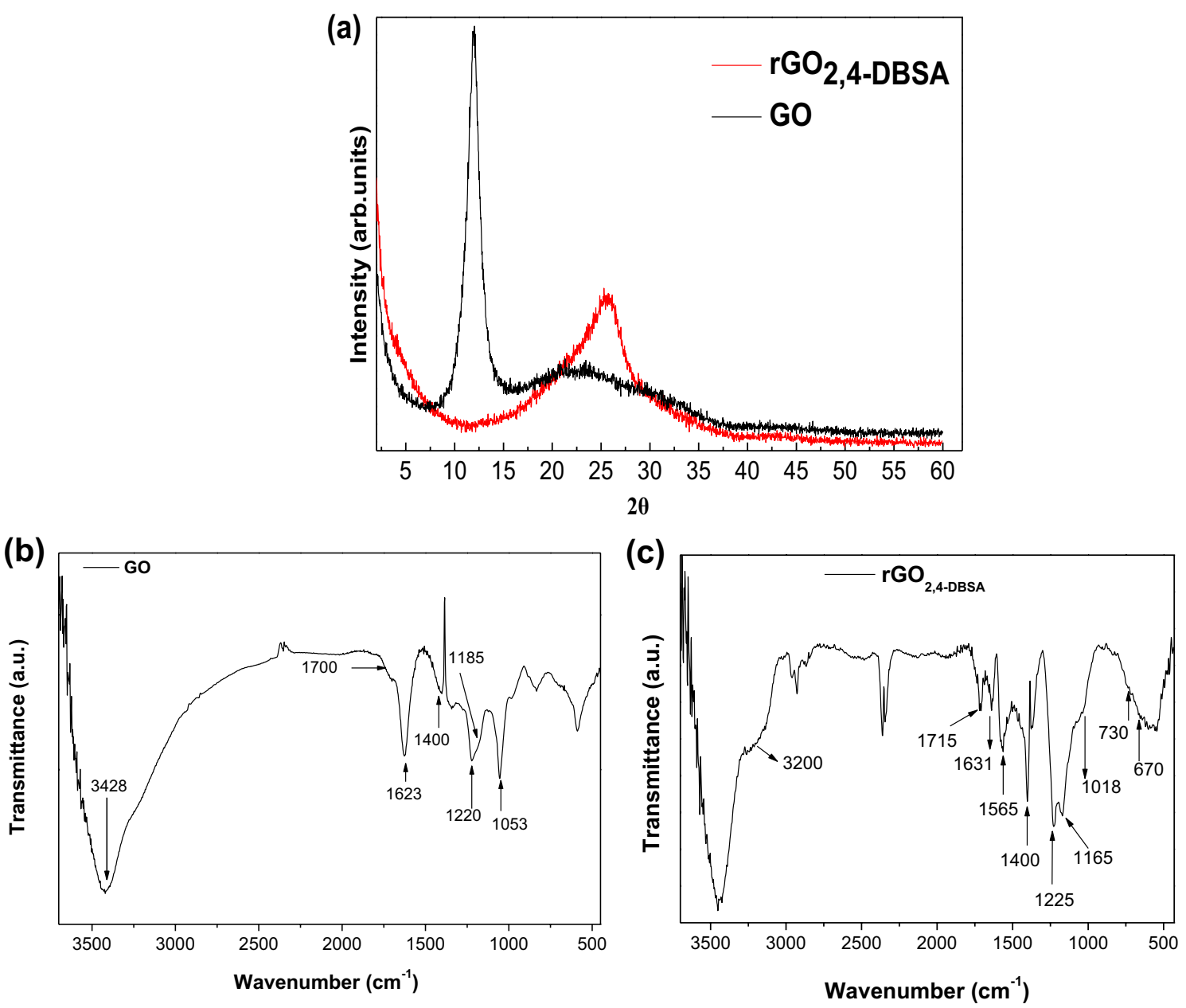

Fig. 3 a Powder XRD patterns of GO, $\mathrm{rGO}_{2,4-D B S A}$ after $5 \mathrm{~h}$ reflux. FT-IR spectra of $\mathbf{b} \mathrm{GO}, \mathbf{c}$ rGO 2,4-DBSA

$286.2 \mathrm{eV}$ corresponds to C-O bonds (hydroxy) and represents the $17.3 \%$ of the total carbon, while two additional peaks centered at $287.1 \mathrm{eV}$ and $288.8 \mathrm{eV}$ are attributed to carbonyl and epoxy (29\%) and carboxyl groups (39.2\%) respectively $[8,60]$. After the reduction/functionalization treatment of GO with 2,4-DBSA, the successful reduction of $\mathrm{GO}$ is clearly observed from the $\mathrm{C} 1 \mathrm{~s}$ peak (Fig. 4b-left). The main $\mathrm{C}-\mathrm{C}$ peak of the aromatic skeleton of graphene increased significantly from $14.4 \%$ for $\mathrm{GO}$ to $61 \%$ for the final $r \mathrm{GO}_{2,4-\mathrm{DBSA}}$. This huge increase is owing to the restoration of $\mathrm{C}=\mathrm{C}$ bonds from the several oxygen functional groups of GO, as well as to the presence of 2,4-DBSA on the surface of $\mathrm{rGO}_{2,4-\mathrm{DBSA}}$. The next peak is slightly increased from $17.3 \%$ to $21 \%$ and is slightly shifted from $286.2 \mathrm{eV}$ to $285.9 \mathrm{eV}$ indicating the contribution of $\mathrm{C}-\mathrm{O}, \mathrm{C}-\mathrm{N}$ and $\mathrm{C}-\mathrm{S}$ bonds which is related to the presence of 2,4-DBSA in the $r \mathrm{GO}$ surface. Finally, an immense reduction of the carboxylic groups from $39.2 \%$ for $\mathrm{GO}$ to just $4.7 \%$ for $r \mathrm{GO}_{2,4-\mathrm{DBSA}^{\prime}}$ as well as a significant reduction of carbonyl groups from 29 to $11.0 \%$ was also observed. All these changes in the
C1s peak reveal the excellent reduction of the oxygen functional groups by the 2,4-DBSA. An extra photoelectron peak observed at $290.2 \mathrm{eV}$ is often attributed to $\pi-\pi$ interactions, which in this case could be attributed to the interaction between the reduced graphenic surfaces or between the aromatic ring of 2,4-DBSA and the rings of the $r G O$ surface. The presence of 2,4-DBSA on the $r G O$ surface is further demonstrated from the S2p (Fig. 4a-right) and N1s photoelectron spectra (Fig. 4b-right). The doublet peak ( $2 p 1 / 2$ and $2 \mathrm{p} 3 / 2)$ of S2p photoelectron spectra centered at $168.1 \mathrm{eV}$ is attributed to the $\mathrm{O}=\mathrm{S}=\mathrm{O}$ groups of 2,4-DBSA, while there is no indication for the formation of $\mathrm{S}-\mathrm{O}-\mathrm{C}$ bond which is indicated at lower binding energies. Finally, the N1s photoelectron spectra of functionalized $r \mathrm{GO}_{2,4 \text {-DBSA }}$ is fitted by two peaks one at lower binding energies $(399.5 \mathrm{eV})$ due to the $\mathrm{C}-\mathrm{N}-\mathrm{C}$ formation representing $36.2 \%$ of the total nitrogen amount and one at $400.4 \mathrm{eV}$ from the $\mathrm{N}-\mathrm{C}(\mathrm{O})$ representing $63.8 \%$ of the total nitrogen amount. Finally, no indication of charged $-\mathrm{NH}_{3}{ }^{+}$groups was observed (Fig. 4b-right) [58]. Elemental 

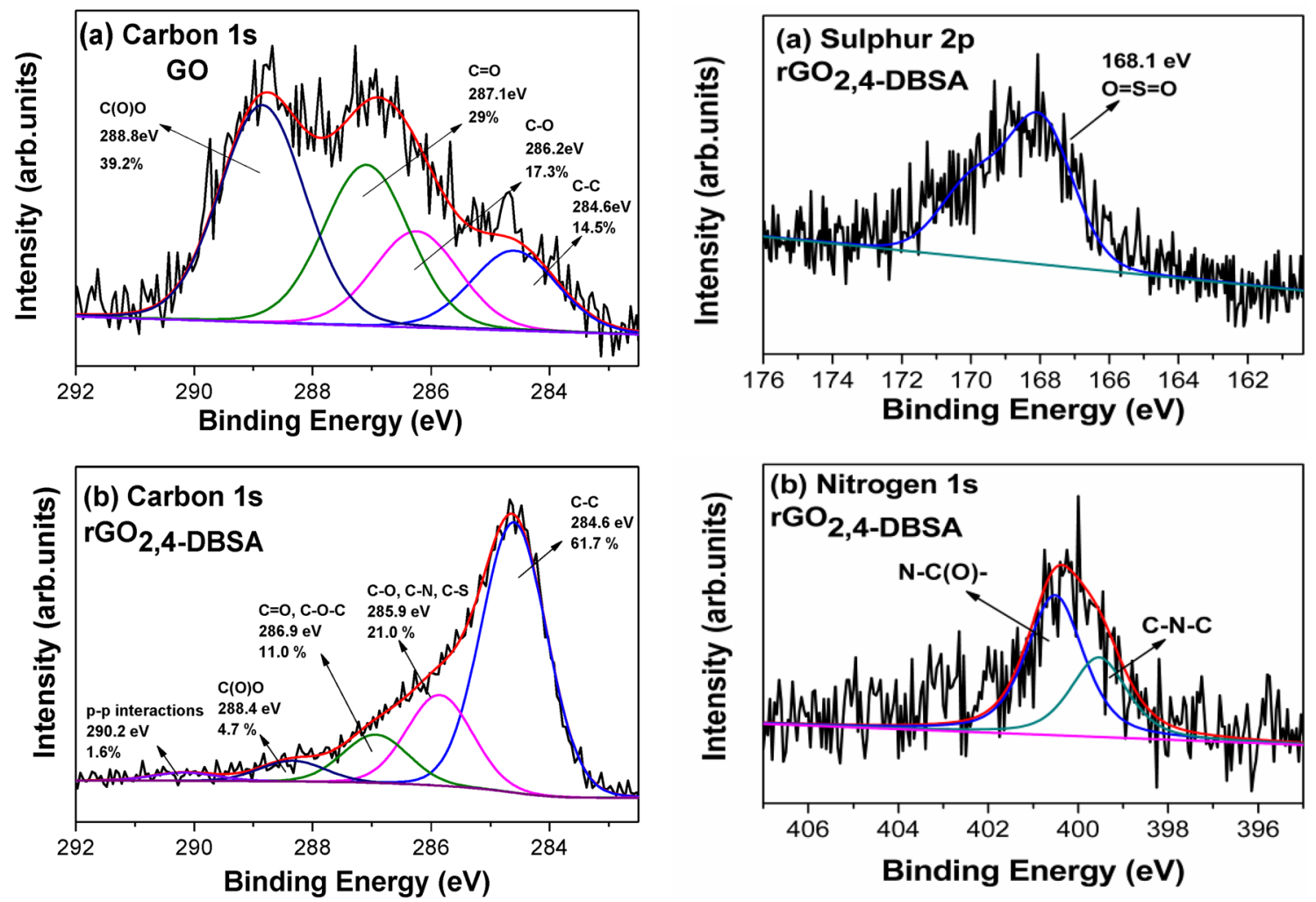

Fig. 4 (left) a C1s photoelectron spectra of GO. b C1s photoelectron spectra of $\mathrm{rGO}_{2,4-\mathrm{DBSA}}$. (right) a Sulphur $2 \mathrm{p}$ photoelectron spectra of $\mathrm{rGO}_{2,4-\mathrm{DBSA}} \cdot \mathbf{b}$ Nitrogen $1 \mathrm{~s}$ photoelectron spectra of $\mathrm{rGO}_{2,4-\mathrm{DBSA}}$

composition analysis reveals the atomic percentage of each element before and after reduction. For the starting graphite oxide the atomic percentage of carbon was $67 \%$, while the oxygen functional groups represent $33 \%$ of the material. After the reduction/functionalization treatment of GO with 2,4-DBSA, the elemental composition of oxygen is reduced to $9.7 \%$ attesting the successful reduction of $\mathrm{GO}$, while $69.7 \%$ represents the atomic percentage of carbon. Finally, $16.0 \%$ of nitrogen and $4.5 \%$ of sulphur for 2,4-DBSA demonstrate the successful functionalization of GO from 2,4-DBSA.

\subsection{TGA measurements of $\mathrm{GO}, \mathrm{rGO}_{2,4-\mathrm{DBSA}}$}

The thermogravimetric (TGA) behavior of the samples helps to evaluate the level of reduction of $\mathrm{GO}$ by the aromatic sulfonated diamines. The TGA thermograms in argon atmosphere, depicted in Fig. 6a, show the weight loss as a function of temperature. $\mathrm{GO}$ exhibits different thermal response compared to $r \mathrm{GO}_{2,4-\mathrm{DBSA}}$. The weight loss of $\mathrm{GO}$ up to $135^{\circ} \mathrm{C}(\sim 15 \%)$ is usually attributed to the evaporation of adsorbed water. The most important weight loss $(\sim 60 \%)$, observed in the region of $180-205^{\circ} \mathrm{C}$, is assigned to water, $\mathrm{CO}$ and $\mathrm{CO}_{2}$ removal after the decomposition of the oxygen-containing functional groups [61]. The weight loss is continued slowly in the region of $200-600^{\circ} \mathrm{C}$, where a 10\% loss is observed and is attributed to the pyrolytic degradation of the carbon skeleton as well as $\mathrm{SO}_{2}, \mathrm{CO}_{2}$ and water removal $[40,47,61]$. In contrast, the $r \mathrm{GO}_{2,4-\mathrm{DBSA}}$ sample shows overall weight loss of $24 \%$ up to $600{ }^{\circ} \mathrm{C}$, reflecting its significantly higher thermal stability owing to the partial deoxygenation and graphitization during the reductive treatments $[40,62] . r G_{2,4-D B S A}$ shows a weight loss of $\sim 6 \%$ up to $180^{\circ} \mathrm{C}$ due to the water removal and a $20 \%$ between 200 and $400{ }^{\circ} \mathrm{C}$ from the pyrolytic removal of the oxygen functional and DBSA groups from the graphene surface (see Fig. 6a). The main carbon skeleton is stable up to $600^{\circ} \mathrm{C}$, indicating the successful graphitization of the procedure.

\subsection{Raman spectroscopy of $\mathrm{GO}, \mathrm{rGO}_{2,4-\mathrm{DBSA}}$}

The Raman spectrum of $\mathrm{GO}, r \mathrm{GO}_{2,4-\mathrm{DBSA}}$ are shown in Fig. 5 . The $D$ band, located at $1350 \mathrm{~cm}^{-1}$, is attributed to the symmetry breaking of perfect sixfold aromatic rings lattice structure due to high concentration of defects related to oxidation. All these $\mathrm{sp}^{3}$ hybridized carbon-carbon bonds, as in tetrahedral structure of diamond, are assigned to the highest optical branch starting from the $\mathbf{K}-\mathrm{A}_{1}$ mode. [63] The $G$ band at $1593 \mathrm{~cm}^{-1}$ is attributed to the in-plane 

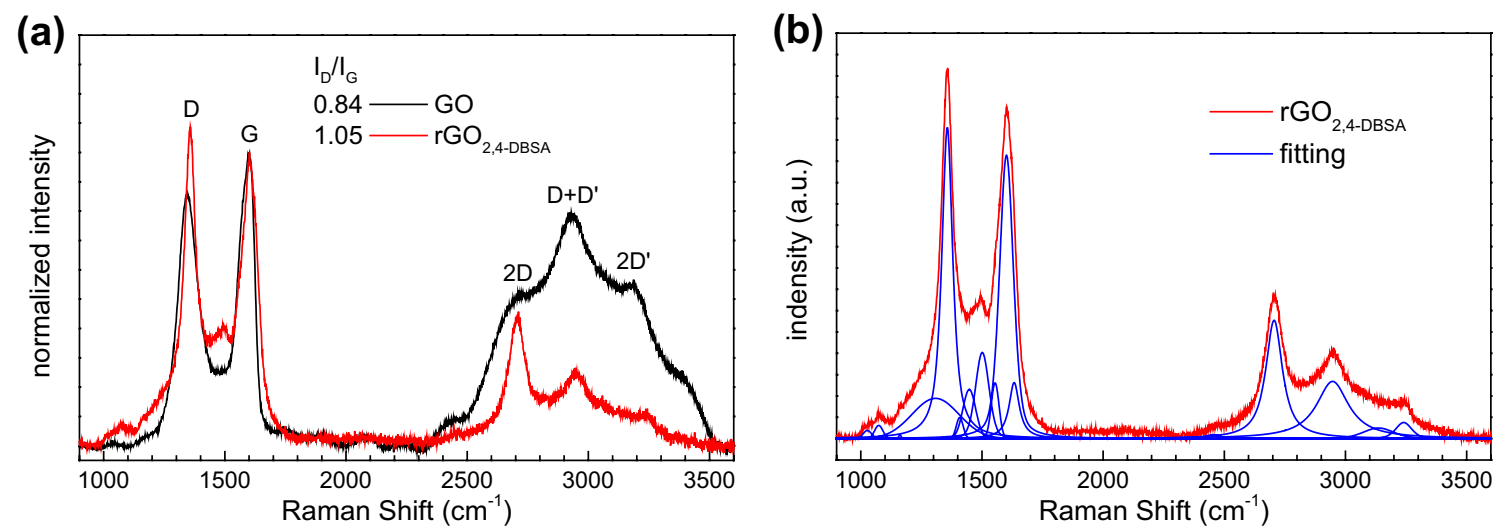

Fig. 5 a Raman spectra of $\mathrm{GO}$ and $r \mathrm{GO}_{2,4-\mathrm{DBSA}}$ after 5-h treatment. b Fitting of $r \mathrm{GO}_{2,4-\mathrm{DBSA}}$ Raman spectrum

(a)

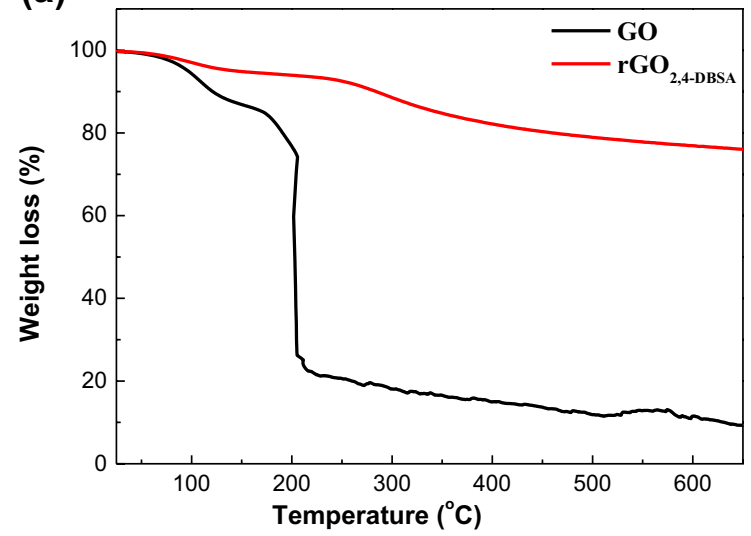

(b)

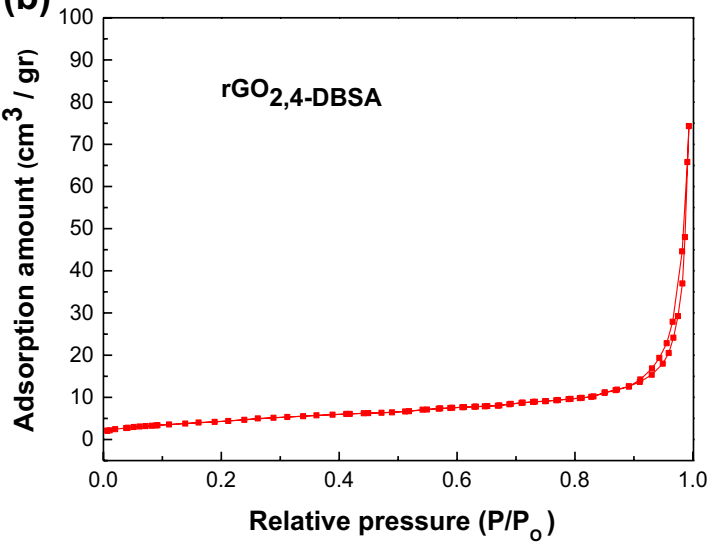

Fig. 6 a TGA of GO and $r \mathrm{GO}_{2,4-\mathrm{DBSA}}$ sample after 5-h treatment. b Nitrogen adsorption and desorption isotherms of the rGO sample after 5-h treatment

bond-stretching motion of pairs of $\mathrm{sp}^{2}$ carbon atoms which assigned to $E_{2 g}$ mode at the Brillouin zone center. In addition, the 2D, $D+D^{\prime}$ and $2 D^{\prime}$ bands appear at 2700 , 2940 and $3200 \mathrm{~cm}^{-1}$. The $D+D^{\prime}$ band at $2940 \mathrm{~cm}^{-1}$ requires a defect for its activation while no defects are required for the activation of $2 D$ and 2D' [64]. In the vicinity of $D$ and $\mathrm{G}$ bands, as it is shown in Fig. 5b, several other bands with lower intensity appear after the reduction/functionalization. All these bands are attributed to carbon bond vibrational coupling deviations in the vicinity of the $\mathrm{sp}^{3}$ defect site due to reduction and functionalization processes [65, 66]. The unusual, relatively high, intensity of these bands is related to the high concentration of phenolic, carbonyl, and carboxylic groups present on the edge and defected carbon rings and to $\mathrm{C}=\mathrm{O}$ stretching vibrations in carboxylic and carbonyl moieties.

The main result here is the sharpness and the size of 2D band. After the reduction/functionalization procedure, the broad and weak $2 \mathrm{D}$ band of $\mathrm{GO}$ become sharper and more intense as a result of the graphitization of the products. The ratio of $I_{D} / I_{G}$ for $r G O_{2,4-D B S A}$ is enhanced compared to $\mathrm{GO}$ indicating that reduction process and functionalization from DBSA alters the structure of $\mathrm{GO}[7,62,64,65$, $67,68]$. It is well documented that the removal of oxygen functional groups during the reduction process creates graphenic networks ( $\mathrm{sp}^{2}$ carbon) which are usually much smaller than the starting $\mathrm{GO}$, leading to an increase in the $\mathrm{I}_{\mathrm{D}} / \mathrm{I}_{\mathrm{G}}$ ratio $[7,9,62,63,69-71]$.

\subsection{Measurements of surface area}

The $\mathrm{N}_{2}$ adsorption isotherm $(77 \mathrm{~K})$ of the $\mathrm{rGO}_{2,4-\mathrm{DBSA}}$ is of type II (IUPAC classification) and is typical of non-porous materials (see Fig. 6b). As the shape of the hysteresis does not point to layered structure such mesopores are probably related to random open space between graphitic domains (e.g. a random card stack structure). BET area measurements of the $r \mathrm{GO}_{2,4-\mathrm{DBSA}}$ yielded values 
of $\sim 17 \mathrm{~m}^{2} \mathrm{~g}^{-1}$, respectively. The surface area of the starting $\mathrm{GO}$ was less than $3 \mathrm{~m}^{2} \mathrm{~g}^{-1}$. Such values are significantly lower than other reported in the literature for $r \mathrm{GO}$ materials using different reductants $[7,72]$ indicating a better stacking of the final product to graphitic domains in accordance with the previous results.

In Fig. 7e, the proposed structure of the product is presented schematically as a conclusion of the presented analysis and the characterization of the product. The 2,4DBSA diamine reduces effectively GO forming few layer graphene nanosheets (approximately 4 layers on average as calculated based on standard Scherrer formula) as derived by XRD and TEM analysis (Figs. 2, 3). In addition, it also acts to functionalize the few layer graphene nanosheets.

\subsection{Electrical measurements}

It is well established that chemical functionalization affects the electrical properties of graphenic materials [73, 74]. In order to specify the effect of the nature of reductants, electrical conductivity of $r \mathrm{GO}$ samples were measured. The reduction of $\mathrm{GO}$ with sulfonated aromatic diamines leads to products with remarkably higher conductivities compared to GO (Table 1). For comparison, when PPD is used as a reductive reagent under exactly the same experimental conditions much lower values of conductivity were recorded compared to those achieved using sulfonated aromatic diamines.

Such high values of conductivity, that are among the highest in the literature [75] in combination with the high dispersibilities of the as prepared $r G O s$ are hardly achieved for chemically reduced GO.

In terms of conductivity of gravure inks thus ranges between 12,000 and $15,400 \mathrm{~S} \mathrm{~m}^{-1}$, values which are among the higher reported in the literature $[29,75,76]$. In Fig. 7f, the stability and flexibility of the conductive ink (Ink-1), drop casted on a filter paper, with or without curved surface is depicted for demonstration. The resistance in both

Table 1 Electrical conductivity $\left(\mathrm{S} \mathrm{m}^{-1}\right)$ of GO, rGOs (dried at $75^{\circ} \mathrm{C}$, after drop casting in paper and pressed at $2 \mathrm{tn}$ )

\begin{tabular}{lc}
\hline Samples & $\begin{array}{l}\text { Conduc- } \\
\text { tivity } \\
\left(\mathrm{S} \mathrm{m}^{-1}\right)\end{array}$ \\
\hline $\mathrm{GO}$ & $9 \times 10^{-4}$ \\
$\mathrm{rGO}_{\mathrm{PPD}}$ & $2 \times 10^{3}$ \\
$\mathrm{rGO}_{2,4 \mathrm{DBSA}}$ & $1.0 \times 10^{5}$ \\
\hline
\end{tabular}

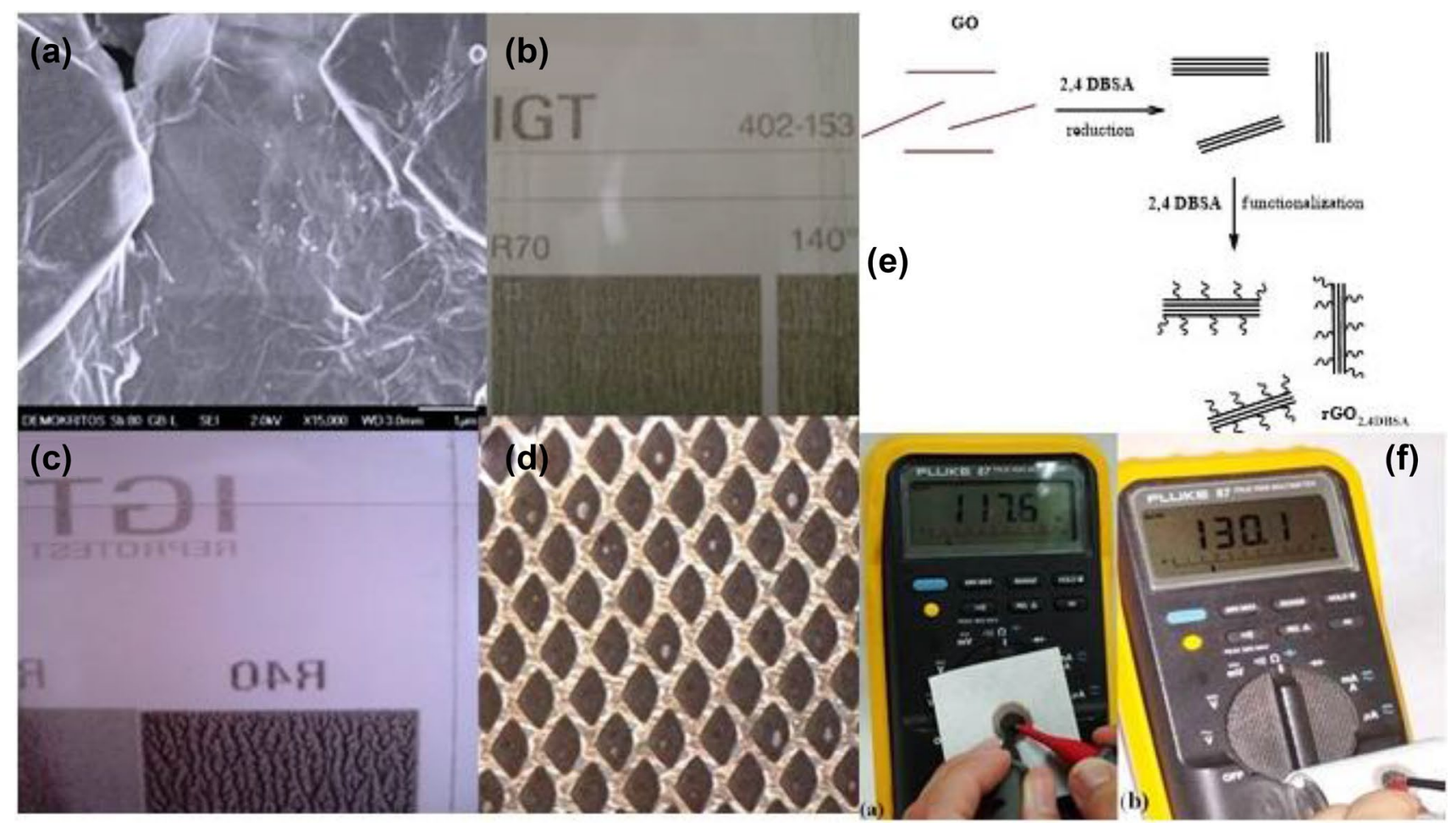

Fig. 7 a SEM image of the Ink-1. Several patterns printed by gravure printing with the Ink-1 on paper using b the 402-153 cylinder with cylinder pressure $300 \mathrm{~N}$ and print speed $24 \mathrm{~m} \mathrm{~min}^{-1}, \mathbf{c}$ the 402-100 cylinder with cylinder pressure $500 \mathrm{~N}$ and print speed $36 \mathrm{~m} \mathrm{~min}^{-1}$ and $\mathbf{d}$ Image from optical microscope of patterns printed with gravure Ink-1. e Schematic representation of the proposed structure of the functionalized graphenic nanostructures $\mathrm{rGO}_{2,4-\mathrm{DBSA}}$. $\mathbf{f}$ Demonstration of the stability and flexibility of the conductive ink drop casted on a filter paper, (left) without or (right) with curved surface 
cases remained the same, while the compression process at 2 tn was not applied in these samples [37].

\subsection{Gravure printing of graphene}

The gravure printing process is one of the highest throughput printing processes of graphic arts. Gravure found application in the field of printed electronics in recent years as a way to low cost electronic devices for huge production volumes. However, this method has always been used extensively in industrial scale applications such as printing of magazines, newspapers, flexible packaging, labels, wallpapers, floor coverings, kitchen units, security documents etc. Gravure is a roll-to-roll printing technology achieving excellent image quality with high production speeds (20-1000 $\left.\mathrm{m} \mathrm{min}^{-1}\right)$ and fine resolution. Also, a wide range of substrates such as paper, board, plastic films and metal foils are printed by this technology. The principle of this method is simple. The printing unit includes the engraved gravure cylinder, the ink fountain, the doctor blade (tightly pressed blade) and the impression roller. The process comprises an image engraving onto the surface of gravure cylinder in the form of cells acting as ink wells. The gravure cylinder is immersed in the ink fountain filling the cells of the gravure cylinder. The ink is removed from the non-image by blades in order to have ink only in the cells. The substrate is consequently rolled between the gravure cylinder and the impression cylinder. Applying suitable pressure, the ink is transferred from cylinder cells to the substrate [77]. The gravure process requires low viscosity inks (0.05-0.20 Pa s) combined with rapid solvent evaporation and formulated from soluble materials or nanoparticle dispersions [78]. The thickness of the ink layer on the substrate varies between 0.8 and $8 \mu \mathrm{m}$.

Gravure inks, Ink-1 and Ink-2, derived from $r \mathrm{GO}_{2,4-\mathrm{DBSA}^{\prime}}$ were prepared as described in the experimental section and showed excellent homogeneity as derived from the SEM image (Si wafer, Fig. 7a). Similar results were observed when a hydrophilic graphene/carbon nanotube hybrid was used as filler for gravure printing ink based on the same resin (NRB 001 L 3099) [21]. From Fig. 7d derives that the printed cells show ink uniformity (complete printed image area coverage). This means that ink parameters (viscosity, surface tension), quality of the substrate, interaction of ink with the substrate and parameters of printing (velocity, cylinder pressure etc.) are in a satisfying level. Selected patterns having promising printability properties are presented in Fig. 7b, c. However, the application of such gravure $\mathrm{rGO}$ inks in printed electronics is a distinguishable scientific work and demands further optimization of the parameters related to printing (e.g. ink formulation, engraving specifications, printability tolerance regards on printing parameters such as printing speed and printing pressure using standard printing test image etc.) [28].

\section{Conclusion}

We have described a facile, efficient, one-pot reduction and functionalization method of graphene oxide using sulfonated aromatic diamine, avoiding harsh chemical treatments or annealing at high temperature. The as prepared reduced/functionalized graphene derivative was fully characterized by various methods and found to possess high dispersibilities in various solvents and excellent electrical conductivity. We have also demonstrated gravure printing of water-based graphene inks on flexible substrates through the formulation of inks from chemically reduced graphene oxide and commercial water-based varnishes. A further optimization of such ink formulations and gravure printing parameters would be the next step for their potential commercial applications in flexible electronics.

Acknowledgements This research has been co-financed by the European Union and Greek national funds through the Operational Program Competitiveness, Entrepreneurship and Innovation, under the call RESEARCH - CREATE - INNOVATE (Project Code: T1EDK-02093). The authors would also like to thank (a) IOANNOU ICR S.A. manufacturer of rotogravure cylinders for the donation of IGT G1-5 printability tester used in this research (b) D. Mantis from Druckfarben Hellas S.A. for the donation of various resin systems, corona treated substrates and helpful discussions and (c) Dr. G. Vlahopoulos for his helpful comments and technical support (d) Prof. D. Triantis and Prof. Elias Stavrakas for the resistivity measurements at the Electronic Devices and Materials Lab - EDML (Department of Electrical and Electronics Engineering, University of West Attica) (e) Dr. R. Gumbiowski from Felix-Schoeller for the donation of various types of $p \_e$ : smart paper. The authors gratefully acknowledge Dr Mary Kollia and the Laboratory of Electron Microscopy and Microanalysis, School of Natural Sciences, University of Patras for the TEM measurements.

\section{Compliance with ethical standards}

Conflict of interest The authors declare that they have no conflict of interest.

\section{References}

1. Novoselov KS, Geim AK, Morozov SV, Jiang D, Zhang Y, Dubonos SV, Gi V, Firsov AA (2004) Electric field effect in atomically thin carbon films. Science 306:666-669. https://doi.org/10.1126/ science.1102896

2. Berger C, Song Z, Li X, Wu X, Brown N, Naud C, Mayou D, Li T, Hass J, Marchenkov AN, Conrad EH, First PN, de Heer WA (2006) Electronic confinement and coherence in patterned epitaxial graphene. Science 312:1191-1196. https://doi.org/10.1126/ science. 1125925

3. Kim KS, Zhao Y, Jang H, Lee SY, Kim JM, Kim KS, Ahn JH, Kim P, Choi JY, Hong BH (2009) Large-scale pattern growth of graphene 
films for stretchable transparent electrodes. Nature 457:706710. https://doi.org/10.1038/nature07719

4. Bourlinos $A B$, Georgakilas V, Zboril R, Steriotis TA, Stubos AK (2009) Liquid-phase exfoliation of graphite towards solubilized graphenes. Small 5:1841-1845. https://doi.org/10.1002/ smll.200900242

5. Hernandez Y, Nicolosi V, Lotya M, Blighe F, Sun Z, De S, McGovern IT, Holland B, Byrne M, Gunko Y, Boland J, Niraj P, Duesberg G, Krishnamurti S, Goodhue R, Hutchison J, Scardaci V, Ferrari AC, Coleman JN (2008) High yield production of graphene by liquid phase exfoliation of graphite. Nat Nanotechnol 3:563-568. https ://doi.org/10.1038/nnano.2008.215

6. Narayan R, Kim SO (2015) Surfactant mediated liquid phase exfoliation of graphene. Nano Converg 2:20. https://doi. org/10.1186/s40580-015-0050-x

7. Stankovich S, Dikin DA, Piner RD, Kohlhaas KA, Kleinhammes A, Jia Y, Wu Y, Nguyen SBT, Ruoff RS (2007) Synthesis of graphenebased nanosheets via chemical reduction of exfoliated graphite oxide. Carbon 45:1558-1565. https://doi.org/10.1016/j.carbo n.2007.02.034

8. Dreyer DR, Park S, Bielawski CW, Ruoff RS (2010) The chemistry of graphene oxide. Chem Soc Rev 39:228-240. https://doi. org/10.1007/978-3-319-15500-5_3

9. Pei S, Cheng HM (2012) The reduction of graphene oxide. Carbon 50:3210-3228. https://doi.org/10.1016/j.carbon.2011.11.010

10. He $\mathrm{H}$, Klinowski J, Forster M, Lerf A (1998) A new structural model for graphite oxide. Chem Phys Lett 287:53-56. https:// doi.org/10.1016/s0009-2614(98)00144-4

11. Lerf A, He H, Forster M, Klinowski J (1998) Structure of graphite oxide revisited. J Phys Chem B 102:4477-4482. https://doi. org/10.1021/jp9731821

12. Hontoria-Lucas C, López-Peinado AJ, de López-González JD, Rojas-Cervantes ML, Martín-Aranda RM (1995) Study of oxygencontaining groups in a series of graphite oxides: physical and chemical characterization. Carbon 33:1585-1592. https://doi. org/10.1016/0008-6223(95)00120-3

13. Szabó T, Berkesi O, Dékány I (2005) DRIFT study of deuteriumexchanged graphite oxide. Carbon. https://doi.org/10.1016/j. carbon.2005.07.013

14. Li W, Tang XZ, Bin Zhang H, Jiang ZG, Yu ZZ, Du XS, Mai YW (2011) Simultaneous surface functionalization and reduction of graphene oxide with octadecylamine for electrically conductive polystyrene composites. Carbon 49:4724-4730. https://doi. org/10.1016/j.carbon.2011.06.077

15. Kim NH, Kuila T, Lee JH (2013) Simultaneous reduction, functionalization and stitching of graphene oxide with ethylenediamine for composites application. J Mater Chem A 1:1349-1358. https ://doi.org/10.1039/c2ta00853j

16. Herrera-Alonso $M$, Abdala AA, McAllister MJ, Aksay IA, Prud'homme RK (2007) Intercalation and stitching of graphite oxide with diaminoalkanes. Langmuir 23:10644-10649. https:// doi.org/10.1021/la0633839

17. Ma HL, Zhang HB, Hu QH, Li WJ, Jiang ZG, Yu ZZ, Dasari A (2012) Functionalization and reduction of graphene oxide with $p$-phenylene diamine for electrically conductive and thermally stable polystyrene composites. ACS Appl Mater Interfaces 4:19481953. https://doi.org/10.1021/am201654b

18. Chen Y, Zhang X, Yu P, Ma Y (2009) Stable dispersions of graphene and highly conducting graphene films: a new approach to creating colloids of graphene monolayers. Chem Commun. https://doi.org/10.1039/b907723e

19. Aleeva Y, Pignataro B (2014) Recent advances in upscalable wet methods and ink formulation for printed electronics. J Mater Chem C 2:6436-6453. https://doi.org/10.1039/C4TC00618F

20. Georgakilas V, Demeslis A, Ntararas E, Kouloumpis A, Dimos K, Gournis D, Kocman M, Otyepka M, Zboril R (2015) Hydrophilic nanotube supported graphene-water dispersible carbon superstructure with excellent conductivity. Adv Funct Mater 25:14811487. https://doi.org/10.1002/adfm.201403801

21. Koutsioukis A, Georgakilas V, Belessi V, Zboril R (2017) Highly conductive water-based polymer/graphene nanocomposites for printed electronics. Chem Eur J 23(34):8268-8274. https:// doi.org/10.1002/chem.201700997

22. Secor EB, Ahn BY, Gao TZ, Lewis JA, Hersam MC (2015) Rapid and versatile photonic annealing of graphene inks for flexible printed electronics. Adv Mater 27:6683-6688. https://doi. org/10.1002/adma.201502866

23. Secor EB, Hersam MC (2015) Emerging carbon and post-carbon nanomaterial inks for printed electronics. J Phys Chem Lett 6:620-626. https://doi.org/10.1021/jz502431r

24. Secor EB, Prabhumirashi PL, Puntambekar K, Geier ML, Hersam MC (2013) Inkjet printing of high conductivity, flexible graphene patterns. J Phys Chem Lett. https://doi.org/10.1021/jz400644c

25. Capasso A, Del Rio Castillo AE, Sun $H$, Ansaldo A, Pellegrini V, Bonaccorso $F$ (2015) Ink-jet printing of graphene for flexible electronics: an environmentally-friendly approach. Solid State Commun. https://doi.org/10.1016/j.ssc.2015.08.011

26. Torrisi F, Coleman JN (2014) Electrifying inks with 2D materials. Nat Nanotechnol 9:738-739. https://doi.org/10.1038/nnano .2014 .218

27. Ko SH (2016) Low temperature thermal engineering of nanoparticle ink for flexible electronics applications. Semicond Sci Technol 31:073003-0730025. https://doi.org/10.1088/0268$1242 / 31 / 7 / 073003$

28. Hrehorova $E$, Rebros $M$, Pekarovicova A, Bazuin B, Ranganathan A, Garner S, Merz G, Tosch J, Boudreau R (2011) Gravure printing of conductive inks on glass substrates for applications in printed electronics. IEEE/OSA J Disp Technol 7:318-324. https ://doi.org/10.1109/JDT.2010.2065214

29. Secor EB, Lim S, Zhang H, Frisbie CD, Francis LF, Hersam MC (2014) Gravure printing of graphene for large-area flexible electronics. Adv Mater 26:4533-4538. https://doi.org/10.1002/ adma.201401052

30. Kirchmeyer S, Hecker K (2014) LOPE-C exhibition: visitor target groups. Org Print Electron 9. http://www.oe-a.org/docum ents/10179/31903/OE-A_Brochure2013.pdf

31. Knoll T (2016) High-resolution gravure printing of graphene for biomedical applications. Presentation at Advanced Functional \& Industrial Printing conference (AFIP), 2-3 March 2016. Düsseldorf. https://www.graphene-biosensors.eu/modx-2.3.3-pl/ media/pdf/Presentation_Th.Knoll_AFIP2016_komprimiert.pdf

32. Ng WTL, Hu G, Howe RCT, Zhu X, Yang Z, Jones CG, Hasan T (2019) Printing of graphene and related 2D materials technology, formulation and applications. Springer, Berlin. https://doi. org/10.1007/978-3-319-91572-2

33. Xiao G, Li Y, Shi W, Shen L, Chen Q, Huang L (2017) Highly sensitive, reproducible and stable SERS substrate based on reduced graphene oxide/silver nanoparticles coated weighing paper. Appl Surf Sci 404:334-341. https://doi.org/10.1016/j.apsus c.2017.01.231

34. Xiao Y, Huang L, Zhang Q, Xu S, Chen Q, Shi W (2015) Gravure printing of hybrid $\mathrm{MoS}_{2} @ \mathrm{~S}-\mathrm{rGO}$ interdigitated electrodes for flexible microsupercapacitors. Appl Phys Lett 107:013906. https ://doi.org/10.1063/1.4926570

35. Staudenmaier $L$ (1898) Verhafren zur darstellung der graphitsaure. Ber Deutsch Chem Ges 31:1481-1487

36. Xie Y, Sherwood PMA (1990) X-ray photoelectron spectroscopic studies of carbon fiber surfaces. 11. Differences in the surface chemistry and bulk structure of different carbon fibers based on poly (acrylonitrile) and pitch and comparison with various graphite samples. Chem Mater 2:293-299. https://doi. org/10.1021/cm00009a020 
37. Georgakilas V, Koutsioukis A, Petr M, Tucek J, Zboril R (2016) Remarkable enhancement of the electrical conductivity of carbon nanostructured thin films after compression. Nanoscale 8:11413-11417. https://doi.org/10.1039/c5nr09025c

38. Konios D, Stylianakis MM, Stratakis E, Kymakis E (2014) Dispersion behaviour of graphene oxide and reduced graphene oxide. J Colloid Interface Sci 430:108-112. https://doi.org/10.1016/j. jcis.2014.05.033

39. Johnson DW, Dobson BP, Coleman KS (2015) A manufacturing perspective on graphene dispersions. Curr Opin Colloid Interface Sci 20:367-382. https://doi.org/10.1016/j.cocis.2015.11.004

40. Moon IK, Lee J, Ruoff RS, Lee H (2010) Reduced graphene oxide by chemical graphitization. Nat Commun 1:73. https://doi. org/10.1038/ncomms1067

41. Paredes Jl, Marti A, Tasco JMD, Mart A (2008) Graphene oxide dispersions in organic solvents. Langmuir 24:10560-10564. https://doi.org/10.1021/la801744a

42. Park S, An J, Jung I, Piner RD, An SJ, Li X, Velamakanni A, Ruoff RS (2009) Colloidal suspensions of highly reduced graphene oxide in a wide variety of organic solvents. Nano Lett 9:1593-1597. https://doi.org/10.1021/nl803798y

43. Mao S, Pu H, Chen J (2012) Graphene oxide and its reduction: modeling and experimental progress. RSC Adv. https://doi. org/10.1039/c2ra00663d

44. Dikin DA, Stankovich S, Zimney EJ, Piner RD, Dommett GHB, Evmenenko G, Nguyen ST, Ruoff RS (2007) Preparation and characterization of graphene oxide paper. Nature 448:457-460. https://doi.org/10.1038/nature06016

45. Kuila T, Bose $S$, Khanra P, Kumar A, Kim NH, Lee HL (2012) A green approach for the reduction of graphene oxide by wild carrot root. Carbon 50:914-921. https://doi.org/10.1016/j.carbo n.2011.09.053

46. Thomas HR, Marsden AJ, Walker M, Wilson NR, Rourke JP (2014) Sulfur-functionalized graphene oxide by epoxide ring-opening. Angew Chemie Int Ed 126:1-7. https://doi.org/10.1002/ anie.201404002

47. Mirza-Aghayan M, Molaee Tavana M, Boukherroub R (2016) Sulfonated reduced graphene oxide as a highly efficient catalyst for direct amidation of carboxylic acids with amines using ultrasonic irradiation. Ultrason Sonochem 29:371-379. https:// doi.org/10.1016/j.ultsonch.2015.10.009

48. Stankovich S, Piner RD, Nguyen SBT, Ruoff RS (2006) Synthesis and exfoliation of isocyanate-treated graphene oxide nanoplatelets. Carbon 44:3342-3347. https://doi.org/10.1016/j.carbo n.2006.06.004

49. Si Y, Samulski E (2008) Synthesis of water soluble graphene. Nano Lett 8:1679-1682

50. Qiao SJ, Xu XN, Qiu Y, Xiao HC, Zhu YF (2016) Simultaneous reduction and functionalization of graphene oxide by 4-hydrazinobenzenesulfonic acid for polymer nanocomposites. Nanomaterials 6:29. https://doi.org/10.3390/nano6020029

51. Verma S, Dutta RK (2015) A facile method of synthesizing ammonia modified graphene oxide for efficient removal of uranyl ions from aqueous medium. RSC Adv 5:77192-77203. https://doi. org/10.1039/C5RA10555B

52. Guo H, Wang X, Qian Q, Wang F, Xia X (2009) A green approach to the synthesis of graphene nanosheets. ACS Nano 3:2653-2659. https://doi.org/10.1021/nn900227d

53. Kellici S, Acord J, Ball J, Reehal HS, Morgan D, Saha B (2014) A single rapid route for the synthesis of reduced graphene oxide with antibacterial activities. RSC Adv 4:14858-14861. https:// doi.org/10.1039/c3ra47573e

54. Lin Z, Yao Y, Li Z, Liu Y, Li Z, Wong CP (2010) Solvent-assisted thermal reduction of graphite oxide. J Phys Chem C 114:1481914825. https://doi.org/10.1021/jp1049843
55. Li M, Liu Z, Ruan J, Chen X, Xu F, Chen X, Lu X, Yang S (2014) Noncovalently grafting sulfonic acid onto graphene oxide for improved hole transport in polymer solar cells. RSC Adv 4:53999-54006. https://doi.org/10.1039/C4RA11305E

56. Kuila T, Khanra P, Kim NH, Choi SK, Yun HJ, Lee JH (2013) Onestep electrochemical synthesis of 6-amino-4-hydroxy-2-napthalene-sulfonic acid functionalized graphene for green energy storage electrode materials. Nanotechnology 24:365706365716. https://doi.org/10.1088/0957-4484/24/36/365706

57. Amer I, Mokrani T, Jewell L, Young DA, Vosloo HCM (2015) Synthesis and characterization of sulfonated poly(p-phenylenediamine) prepared by different procedures. Polymer 66:230-239. https://doi.org/10.1016/j.polymer.2015.04.050

58. Tang G, Jiang ZG, Li X, Bin Zhang H, Dasari A, Yu ZZ (2014) Three dimensional graphene aerogels and their electrically conductive composites. Carbon 77:592-599. https://doi.org/10.1016/j.carbo n.2014.05.063

59. Han N, Cuong TV, Han M, Ryu BD, Chandramohan S, Park JB, Kang JH, Park YJ, Ko KB, Kim HYHK, Ryu JH, Katharria YS, Choi GJ, Hong C (2013) Improved heat dissipation in gallium nitride light-emitting diodes with embedded graphene oxide pattern. Nat Commun 4:1452. https://doi.org/10.1038/ncomms2448

60. Shang J, Ma L, Li J, Ai W, Yu T, Gurzadyan GG (2012) The origin of fluorescence from graphene oxide. Sci Rep 2:792. https://doi. org/10.1038/srep00792

61. Eigler S, Dotzer C, Hof F, Bauer W, Hirsch A (2013) Sulfur species in graphene oxide. Chem A Eur J 19:9490-9496. https://doi. org/10.1002/chem.201300387

62. Feng H, Cheng R, Zhao X, Duan X, Li J (2013) A low-temperature method to produce highly reduced graphene oxide. Nat Commun 4:1537-1539. https://doi.org/10.1038/ncomms2555

63. Ferrari AC (2007) Raman spectroscopy of graphene and graphite: disorder, electron-phonon coupling, doping and nonadiabatic effects. Solid State Commun 143:47-57. https://doi. org/10.1016/j.ssc.2007.03.052

64. Cançado LG, Jorio A, Ferreira EHM, Stavale F, Achete CA, Capaz RB, Moutinho MVO, Lombardo A, Kulmala TS, Ferrari AC (2011) Quantifying defects in graphene via Raman spectroscopy at different excitation energies. Nano Lett 11:3190-3196. https://doi. org/10.1021/NL201432G

65. Vecera P, Chacón-Torres JC, Pichler T, Reich S, Soni HR, Görling A, Edelthalhammer K, Peterlik H, Hauke F, Hirsch A (2017) Precise determination of graphene functionalization by in situ Raman spectroscopy. Nat Commun 86:15192. https://doi.org/10.1038/ ncomms15192

66. Claramunt S, Varea A, López-Díaz D, Velázquez MM, Cornet A, Cirera A (2015) The importance of interbands on the interpretation of the Raman spectrum of graphene oxide. J Phys Chem C 119:10123-10129. https://doi.org/10.1021/acs.jpcc.5b01590

67. Chua CK, Pumera M (2015) Monothiolation and reduction of graphene oxide via one-pot synthesis: hybrid catalyst for oxygen reduction. ACS Nano 9:4193-4196

68. Englert JM, Dotzer C, Yang G, Schmid M, Papp C, Spiecker E, Hauke F, Hirsch A, Gottfried JM, Steinru H (2011) Covalent bulk functionalization of graphene. Nat Chem 3:279-286. https://doi. org/10.1038/NCHEM.1010

69. Tuinstra F, Koenig L (1970) Raman spectrum of graphite. J Chem Phys 53:1126-1130. https://doi.org/10.1063/1.1674108

70. Lucchese MM, Stavale F, Ferreira EHM, Vilani C, Moutinho MVO, Capaz RB, Achete CA, Jorio A (2010) Quantifying ion-induced defects and Raman relaxation length in graphene. Carbon 48:1592-1597. https://doi.org/10.1016/j.carbon.2009.12.057

71. Eigler S, Hirsch A (2014) Chemistry with graphene and graphene oxide-challenges for synthetic chemists. Angew Chemie Int Ed 53:7720-7738. https://doi.org/10.1002/anie.201402780 
72. Park S, An J, Potts JR, Velamakanni A, Murali S, Ruoff RS (2011) Hydrazine-reduction of graphite and graphene oxide. Carbon 49:3019-3023. https://doi.org/10.1016/j.carbon.2011.02.071

73. Santos EJG, Ayuela A, Sánchez-Portal D (2012) Universal magnetic properties of sp 3-type defects in covalently functionalized graphene. New J Phys 14:43022. https://doi.org/10.1088/13672630/14/4/043022

74. Sreeprasad TS, Berry V (2013) How do the electrical properties of graphene change with its functionalization? Small 9:341-350. https://doi.org/10.1002/smll.201202196

75. Li W, Li F, Li H, Su M, Gao M, Li Y, Su D, Zhang X, Song Y (2016) Flexible circuits and soft actuators by printing assembly of graphene. ACS Appl Mater Interfaces 8:12369-12376. https:// doi.org/10.1021/acsami.6b04235

76. Yang W, Wang C (2016) Graphene and the related conductive inks for flexible electronics. J Mater Chem C 4:7193-7207. https ://doi.org/10.1039/C6TC01625A

77. Kipphan H (2001) Handbook of print media. Springer, Berlin. https://doi.org/10.1007/978-3-540-29900-4

78. Kahn BE (2015) Patterning processes for flexible electronics. Proc IEEE. https://doi.org/10.1109/JPROC.2015.2401553 